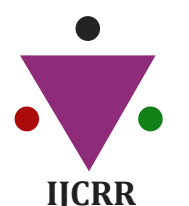

Section: Healthcare

Sci. Journal Impact

Factor: 6.1 (2018)

ICV: 90.90 (2018)

(c) (i) (3)

Copyright@IJCRR

\section{Exploring Quality of Life and Perceived Experiences Among Couples Undergoing Fertility Treatment in Western India: A Mixed Methodology}

\section{Sonali Banerjee ${ }^{1}$, Mary Mathews N. ${ }^{2}$}

'PhD Scholar, MGM Institute of Health Sciences, Kamothe, Navi Mumbai, India; ${ }^{2}$ Former Principal, MGM College of Nursing, Navi Mumbai, India.

\title{
ABSTRACT
}

Background: Diagnosis and related advanced fertility treatments are multifaceted and protracted with unstipulated outcomes. There remains a risk of bodily burden, psychological distress, furthermore may impact the quality of life among infertile couples.

Objectives: Study was aimed to 1. assess the quality of life among infertile couples undergoing fertility treatment and compare it between respective partners. 2. explore in-depth their perceived experiences.

Methods: Explanatory mixed method design with sequential data collection, nested sampling technique was adopted. Participants included 300 women \& 300 men attending a fertility clinic at a tertiary hospital. 300 couples were administered FertiQoL questionnaire for quantitative data collection while qualitative data were collected by in-depth interview of eleven couples, and thematic analysis was done. Ethical compliance was maintained throughout the study.

Analysis: Socio-demographic data revealed that the mean age of the wives and husbands were $31.17 \pm 5.4$ and $35.4 \pm 5.6$ years respectively. BMI was higher in $39.7 \%$ of wives and $58.7 \%$ of husbands. The mean of total FertiQoL score of 300 couples in Western India was $29.3 \pm 9.2$. Wives had significantly lesser scores than their husbands in emotional $\left(p=0.007^{*}\right)$, social $\left(p=0.001^{*}\right)$ and environmental $\left(p=0.013^{*}\right)$ subscales. The total FertiQoL mean scores were significantly lower among wives $\left(p=0.001^{*}\right)$. Themes emerged from qualitative data as a societal burden, physical pain and distress, monetary crisis and interpersonal problems.

Conclusion: Infertile couples in western India reported poor QoL. Wives have poorer FertiQoL scores as compared to their partners. Couples undergoing fertility treatment face various challenges jeopardising their quality of life.

Key Words: Infertility, Quality of life, FertiQoL, Experiences of infertile couples.

\section{INTRODUCTION}

Reproduction and enduring the lineage are amid the most innate and important instincts of all living beings. Indian Statistics (2017) showed a decline in total fertility rate (TFR), 2.4 in rural areas and 1.7 in urban. Western state Maharashtra reported TFR 1.7. ${ }^{1}$ Furthermore, global statistics conjecture that approximately $15 \%$ of the reproductive age population is affected by infertility. Indian scenario, as per WHO records shows a wide-ranging figure i.e. 3.9 to $16.8 \%$ as per different states. ${ }^{2}$ Both the datasets implied a decline in TFR on other hand an incline in infertility prevalence.

In the past few decades, fertility treatment has been advanced immensely, concurrently awareness and treatment-seeking behaviour also displays a steady upsurge among the infertile couples. The labelling of the infertility diagnosis itself triggers consequences like changes in emotions, thoughts, and beliefs of the couples. They not only face a medical condition but also pertinent challenges. As per the description given by the World Health Organization (WHO), Quality of life is individuals' perceptions of their position in life in the context of culture and the value systems where they live . $^{3}$ Thus, it may be considered that fertility QoL encompasses a replication of Indian infertile couples' life status during their infertile period. Inability to conceive eventually trails to stigma, eviction and social anguish in milieu to Indian societal framework as parentage is considered with utmost repute, significance and urgency. Both partners endure tremendous family and social pressure for commencing a family. Infertility is an intricate and situational predicament predisposing

\section{Corresponding Author:}

Sonali Banerjee, Ph D Scholar, MGM Institute of Health Sciences, Kamothe, Navi Mumbai 410209, India. Email: sonalibaries@gmail.com

ISSN: 2231-2196 (Print)

Received: 14.07 .2020
ISSN: 0975-5241 (Online)

Revised: 22.08 .2020
Accepted: 03.09.2020
Published: 22.09 .2020 
to psychologically threatening, emotionally traumatic, monetary challenging, and physically painful due to the diagnostic-curative procedures.

Furthermore, enormous marital life unhappiness and repetitive pregnancy trials play a vital role in worsening the experiences and the couple, especially women are predisposed to marital distress. ${ }^{4}$ As spouses become more discreet toward one another, their marriage life may also be adversely altered affecting their Quality of life.

With extensive literature review, it was observed that QoL was explored typically among infertile women, very few studies were conducted considering both the partners. However, an in-depth study about the impact on the quality of life of such couples is less into documentation with Indian population context. The present study was conceptualized to explore exhaustively the quality of life among couples undergoing fertility treatment, and compare it between respective partners and also to explore in-depth the related experiences of infertile couples.

\section{MATERIALS AND METHODS}

Explanatory mixed method design with sequential data collection (QUAL -> Quan) ${ }^{5}$ was aptly adopted. The qualitative data was collected to support the quantitative findings. The study was merged at the time of interpretation of findings. The current study was conducted as a part of the larger project, from October 2018 to June 2020 in various phases. Settings of the study were at a tertiary hospital and research centre, at Navi Mumbai, with a super specialised fertility clinic.

Couples who were willing to participate, women aged above 18 years and below 50 years, men aged above 21 years and below 55 years and who can read, write, speak and understand English/Hindi/ Marathi were included in the study. As per exclusion criteria couples with secondary infertility, previous history of In Vitro fertilization treatment, were not enrolled in the study. For creating better participation and interaction, the couple- based dyadic approach was incorporated. All participants were interviewed in one or two sessions lasting approximately 30 to 60 minutes. This study was part of research approved by the Ethics Committee for Research on Human Subjects (ECRHS) at MGM Institute of Health Sciences, Kamothe, Navi Mumbai, approval letter: MGMIHS/ RES/02/2017-18 dated 20.03.2018. Before the commencement of the project, all written permissions were procured from authorities. Before the interviews, participant couples were acquainted with the research aims and informed consent was obtained from both the partners. Confidentiality was the utmost priority of the study and they could withdraw from the project as desired.

Data collection was done with the sequential approach, 346 couples were screened for the study, 300 couples (300 wom- en, 300 men) were finally selected through purposive sampling technique with maximum variations for quantitative strand. Qualitative data was collected by in-depth interview of eleven couples, using nested sampling until data saturation. All couple of interviews were recorded and transcribed. Conventional thematic analysis was done. The trustworthiness of the data was ensured by maximal variation, peer debriefing and $3^{\text {rd }}$ party review of transcripts.

The tools for data collection: a. Socio-demographic sheet, $b$. Standardised FertiQoL questionnaire to elicit QOL among the infertile couples. FertiQoL is a worldwide validated tool to quantify the quality of life of couples undergoing fertility issues and was used with author permission. ${ }^{6}$ FertiQoL consists of 36 questions, two general questions, Core FertiQoL with 24 questions, four domains ( emotional, mind-body, relational and social ), and optional Treatment module with 10 questions and two subscales (environment and tolerability) It is available in English and Hindi, translated to Marathi (Cronbach's alpha internal consistency $r=0.89$ ). Scaled scores range from 0 to 100 , lower QoL was inferred with lower scores.

Statistical analysis was performed using SPSS 21.0 software. Categorical variables were expressed as frequency and percentage, continuous variables as mean and standard deviations. Comparisons were done using the Mann-Whitney $\mathrm{z}$ test and two-sample $\mathrm{z}$ test. Statistical significance was inferred with a p-value less than 0.05 .

\section{RESULTS}

\section{Quantitative Data Analysis}

Data were analysed for 300 couples with $100 \%$ participation. The mean age of the wives and husbands $31.17 \pm 5.4$ and $35.4 \pm 5.6$ years respectively. Both the groups were homogenous in terms of religion and education as shown in Table 1 below.

$\begin{array}{lccc}\text { Table 1: Demographics of wives and husbands } \\ \begin{array}{l}\text { Variables } \\ \text { Wife } \\ \text { Age* }\end{array} & \begin{array}{c}\text { Husband } \\ (\mathbf{n}=300)\end{array} & \text { p value } \\ 20-24 & 38(12.7) & 02(0.7) & 0.001 \\ 25-29 & 80(26.7) & 38(12.7) & \\ 30-34 & 94(31.3) & 114(38.0) & \\ 35-39 & 67(22.3) & 68(22.6) & \\ 40-44 & 20(6.7) & 57(19.0) & \\ 45-50 & 1(0.3) & 21(7.0) & \\ \text { Religion } & & & \\ \text { Buddhist } & 11(3.7) & 11(3.7) & 0.917\end{array}$


Table 1: (Continued)

\begin{tabular}{lccc} 
Variables & $\begin{array}{c}\text { Wife } \\
(\mathbf{n}=300)\end{array}$ & $\begin{array}{c}\text { Husband } \\
(\mathbf{n}=300)\end{array}$ & p value \\
Christian & $6(2.0)$ & $7(2.3)$ & \\
Hindu & $259(86.3)$ & $258(86.0)$ \\
Muslim & $18(6.0)$ & $18(6.0)$ \\
Sikh & $6(2.0)$ & $6(2.0)$ & \\
Education & & & \\
Primary & $9(3.0)$ & $8(2.7)$ \\
Middle School & $19(6.3)$ & $13(4.3)$ \\
Secondary & $57(19.0)$ & $45(15.0)$ \\
Intermediate & $62(20.7)$ & $84(28.0)$ \\
Graduation & $120(40.0)$ & $108(36.0)$ \\
Post-Graduation & $33(11.0)$ & $42(14.0)$ \\
Occupation* & & \\
Housewife & $160(53.3)$ & $\mathrm{NA}$ \\
Unskilled & $\mathrm{o}(\mathrm{o})$ & $1(0.3)$ \\
Semi-skilled & $2(0.7)$ & $46(15.3)$ \\
Skilled & $67(22.3)$ & $157(52.4)$ \\
Clerical & $21(7.0)$ & $30(10.0)$ \\
Semi-professional & $49(16.4)$ & $61(20.3)$ \\
Professional & $1(0.3)$ & $5(1.7)$ \\
\hline
\end{tabular}

Significant Difference in terms of age \& occupation.

Around $27.4 \%$ of the wives quit their jobs to conform with the frequent schedules for hospital appointments and treatment. Revised Kuppuswami scale ${ }^{7}$ was incorporated to determine the socio-economic status of the couples, it was seen that the majority $(67 \%)$ couples belonged to Upper middle class. The majority $(58 \%)$ of the couples stayed as a nuclear family, around $19.9 \%$ has separated from joint families due to family pressure. Body mass index revealed that 119 (39.7\%) wives and $176(58.7 \%)$ were overweight. As per personal habits, women were non-smokers and non-alcoholics. Among men $27.8 \%$ were smokers and $48.3 \%$ reported occasional alcohol indulgence.

Reproductive health per se, the average age at marriage of women was $24.9 \pm 4.7$ years, men were $29.2 \pm 5.0$ years. Majority $36 \%$ were married for 3 to 6 years and $56.3 \%$ reported duration of infertility less than 3 years. Around $74 \%$ of couples reported the frequency of physical relation was less than 2 times/week, and around $56.7 \%$ had ovulation unmatched relationship. Majority i.e. $70 \%$ of the couples were staying together, $14 \%$ of them stayed separately due to different location of the job of spouse and remaining $16 \%$ stayed separately due to personal issues with the duration of 1 to 3 years.

As per psychological aspects, majority i.e. $88.0 \%$ wives were stressed while in a physical relationship with the partner, whereas $70.7 \%$ of husbands reported as stressed. To- wards the treatment expenses, the majority $(54.7 \%)$ of the couples expressed that they would meet the financial expenses by taking loans.

Infertility causes identified female index case: $39.3 \%$, male index case: $22 \%$, mixed: 21 , idiopathic: $17.7 \%$. Majority of the women i.e. $27.3 \%$ had the polycystic ovarian syndrome, whereas, among men, $27.3 \%$ were diagnosed with oligospermia.

Quality of life was measured among the infertile couples using the FertiQoL tool. The mean FertiQoL score of infertile couples was $29.3 \pm$ 9.2. depicted in Fig1 as below.

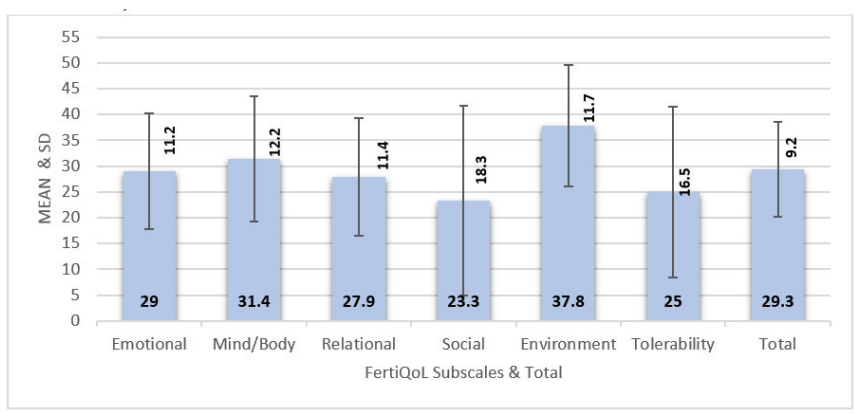

Figure 1: The mean FertiQoL scores of 300 infertile couples (error bars represent standard deviations).

The comparison was done between the partner scores. Wives had significantly lower scores than respective partners about emotional and social, treatment environment domains $(p<0.05)$, whereas mind-body and relational, tolerability domains it was similarly lower scores for both $(\mathrm{p}>0.05)$. Total FertiQoL scores were significantly lower among wives $(\mathrm{p}<0.05)$ indicating wives had poorer QoL as shown in Table2 below.

\section{Table 2: Comparison of FertiQoL scores of wives with husbands.}

\begin{tabular}{lccc}
$\begin{array}{l}\text { FertiQoL } \\
\text { Scores }\end{array}$ & $\begin{array}{c}\text { Wife }(\mathbf{n = 3 0 0}) \\
\text { Mean } \pm \text { SD }\end{array}$ & $\begin{array}{c}\text { Husband } \\
(\mathbf{n}=300) \\
\text { Mean } \pm \text { SD }\end{array}$ & p-value \\
\hline $\begin{array}{l}\text { Core FertiQoL } \\
\quad \text { Emotional* }\end{array}$ & $27.9 \pm 9.7$ & $30.1 \pm 12.4$ & 0.007 \\
$\quad$ Mind/body & $31.3 \pm 13.8$ & $31.6 \pm 10.2$ & 0.358 \\
$\quad$ Relational & $27.4 \pm 11.4$ & $28.5 \pm 11.3$ & 0.127 \\
$\quad$ Social* & $17.6 \pm 13.5$ & $29.0 \pm 20.5$ & 0.001 \\
Treatment FertiQoL $^{*}$ & & & \\
$\quad$ Environment* & $38.8 \pm 11.4$ & $36.7 \pm 12.0$ & 0.013 \\
$\quad$ Tolerability & $24.9 \pm 15.1$ & $25.1 \pm 17.8$ & 0.433 \\
$\quad$ Total FertiQoL & $28.2 \pm 8.5$ & $30.5 \pm 9.8$ & 0.001 \\
\hline
\end{tabular}

*Significant difference between wives and husband scores. Two sample $\mathrm{z}$ test used. 
Couples were also evaluated for the association between selected demographics and FertiQoL scores. Fisher's exact test was used to find the association of Quality of Life with educational status $(p=1.000)$, duration of infertility $(p=0.085)$ and comorbidity $(p=0.847)$. Chi-square test was used for age $(p=0.766)$, diagnosis $(p=0.230)$ Since the $p$-values corresponding to all the variables were greater than 0.05 , none of these variables had a significant association with quality of life among infertile couples.

Qualitative Data Analysis: In-depth interviews of pertinent experiences from eleven couples were taped and transcribed. Content analysis revealed three major themes, few verbatims were put together as before (W denotes wife, $\mathrm{H}$ denotes Husband)

\section{- Societal burden and seclusion}

Mostly all participants reported societal pressure in response to their infertility and were quite uneasy when asked questions about having children.

W2: "Social gatherings are nightmares as everyone is more interested to know about us rather than the celebration. Probing questions and sympathy aches my heart, feel like I am a sinner."

H5: Gossips increase about our visit to a fertility centre, "her man must be having some defect, she looks healthy". It is indeed struggling to lead a normal life. We have consciously stopped attending such ceremonies and meeting people.

\section{- Physical Pain, shame and distress}

W7: Fertility treatment requires many injections to increase my egg quality, they are not only painful, but I am so much worried about the side effects to baby and me. I feel shy while getting the vaginal ultrasound done.

H9: Semen collection at the hospital makes me anxious and stressed.

\section{- Monetary crisis}

W3: The treatment is expensive which includes blood tests, ultrasound, medicines, injection, and procedure. I have put my marriage jewellery for taking the loan. So much anxiety and pain despite all efforts.

H11: Every month when her periods come, my worry sores with the thought of next month expenses on medicines and scans. We are trying with IUI now, if not for IVF we will require borrowing money.

\section{- Interpersonal problems with their respective partners}

W4: "Our marriage is at stake now, as I am unable to conceive, it may end with a Talakh (divorce). It is dying daily bit by bit; we are drifting apart; our arguments and difference of opinions had increased. Whenever we try to talk about our infertility problem it eventually led to an argument. We have almost stopped sharing thoughts and expressing, rather hiding feelings has become a habit.

H4: "I have no problem with her, but I am under tremendous pressure to give a child to the family. She can cry and pour out her emotion, men have to just bear it. I am exhausted balancing between the family and her."

Meta Inferences: The mean FertiQoL score for infertile couples was $29.3 \pm 9.2$. The mean FertiQoL score of wives was $28.2 \pm 8.5$, and husbands had a mean value of $30.5 \pm 9.8$. FertiQoL scores were significantly lower among wives $(p<0.05)$ in comparison to respective partners. The findings were further supported by the thematic analysis of qualitative data, wherein the couples shared various experiences concerning Indian cultural context, which declined the quality of life pertinent to fertility treatment and diagnosis.

\section{DISCUSSION}

There remain a constant peril and burden to conceive, the programmed method to conception, negatively impacting the quality of life of the couples undergoing treatment. With societal pressure, repetitive and prolonged cycles of treatment, furthermore situations worsen incurring mental agony, physical pain and monetary burden. The current study was conceptualised to explore the QoL of such couples. 5,6

\section{Couple demographics}

In the current study, the mean age of the wives and husbands was $31.17 \pm 5.4$ and $35.4 \pm 5.6$ years respectively. Mean age of Portuguese participants in a study was $32.51 \pm 3.92$ for women and $34.77 \pm 4.20$ for men. The findings were similar. It was also reported from the same study that most couples had medium socio-economic status $(72.9 \%)$, whereas subjects in the current study majority (67\%) couples belonged to upper-middle class. ${ }^{8}$

In the current study as per the educational status majority of the wives (40\%), husbands (36\%) were graduates and education had no association with QoL. Previously study done in Turkey ${ }^{9}$ concluded with similar findings, despite higher education, the total FertiQoL scores were low. It can be inferred that advanced education cannot recompense the emotions and QoL. Whereas an Iranian study concluded that lower academic education is associated with lower QoL. ${ }^{10}$

Type of family was classified as a nuclear and joint family, the majority $(58 \%)$ of the couples stayed as the nuclear family, whereas one-fourth of couples were living with extended families as reported in a Turkish study. ${ }^{9}$ 
BMI was higher in $39.7 \%$ of wives and $58.7 \%$ of husbands which is similar to findings of an Indian study with significantly higher BMI, which may be associated with poor treatment outcomes. ${ }^{11}$

Majority 36\% were married for 3 to 6 years and $56.3 \%$ reported duration of infertility less than 3 years, the figures were comparable to $60.6 \%$ with less than 5 years. ${ }^{10}$ Duration of infertility had no association with QoL, whereas the extended duration of infertility was associated with lower scores of mind/bodies, social, tolerability domains and total QoL score $(\mathrm{p}<0.05)$ which probably could be related to secondary infertility. ${ }^{9}$

Majority of the women i.e. $27.3 \%$ had Polycystic Ovarian Syndrome, similar findings were reported from another study done in India wherein PCOS led to the major cause of infertility among women. ${ }^{12}$ Distribution of infertility causes documented in the current study was female index case: $45 \%$, male index case: $23 \%$, mixed: 15 , idiopathic: $17 \%$. These findings were analogous to a study finding where in causes documented female: $41.4 \%$; male: $30.0 \%$; mixed: $12.9 \%$; and idiopathic: $15.7 \%{ }^{9}$

\section{Quality of life among infertile couples}

In the current study, the mean FertiQoL score among infertile couples was $29.3 \pm 9.2$. and the mean FertiQoL score of wives and husbands was $28.2 \pm 8.5$ and $30.5 \pm 9.8$ respectively, inferring significantly lower scores among wives $(p<0.05)$. A study conducted in Iran, the sample consisted of 514 women and 514 men, SF -36 tool was used to assess infertility related QOL. Results revealed that women had poorer quality of life $(\mathrm{p}<0.05)$ about a health-related domain, social functioning role-emotional domain as well as mental health domain Quality of life. ${ }^{13}$. Table 3 below shows the mean FertiQoL scores of women across the globe. ${ }^{9}, 14-17$

\begin{tabular}{|c|c|}
\hline Country & Wife $($ Mean \pm SD $)$ \\
\hline China & $64.54 \pm 16.90$ \\
\hline Turkey & $66.97 \pm 14.35$ \\
\hline Netherland & $70.80 \pm 13.90$ \\
\hline America & $72.30 \pm 14.80$ \\
\hline Germany & $73.00 \pm 12.00$ \\
\hline
\end{tabular}

It was evident that Indian women had poorer QoL as compared to western women, the variances in scores may be linked with the family system and societal framework.

In an Indian study, the raw/unscaled mean scores of women were $17.34,16.12,15.94$ and 16.57 on the domains of emotional, mind-body, relational and social dimensions respectively. ${ }^{11}$ This may be comparable with the findings of the cur- rent study( scaled means: 27.9, 31.3, 27.4, 17.6 ) inferring a diminishing of QoL among the infertile women concerning same country cultural context.

The core FertiQoL scores documented for infertile men with irregular cohabitation was $43.32 \pm 7.72$, and $64.55 \pm 11.17$ with regular cohabitation ${ }^{18}$ whereas in the present study it was much lesser i.e. $30.5 \pm 9.8$.

The study conducted in Taiwan compared the QoL among partners, females had significantly lower $(\mathrm{p}<0.05)$ Core and Treatment FertiQoL $(54.39 \pm 13.52$ vs $60.63 \pm 14.07$ and $56.03 \pm 10.71$ vs $59.13 \pm 12.44) .{ }^{19}$ Women scored significantly lower on the FertiQoL total scores $[\mathrm{B}=-6.31 ; 95 \%$ confidence interval $(\mathrm{CI})=-7.63$ to 4.98$]$ and three of the FertiQoL subscales (Emotional, Mind-Body and Social) than their partners, indicating lower QoL. ${ }^{20}$ Even though the scores were higher but the comparison was congruent with present study findings inferring women have lower QoL than men irrespective of geographical locations.

\section{Strength and Limitation}

The explanatory mixed methodology emerged as the strength of the research, reasons for poor QoL among infertile couples in western India was explored in-depth, giving comprehensiveness and clarity. Relevant perspectives in-relation to Indian context have been brought to light to further justify the poorer QoL perceived by infertile couples. Limitations of the study were in terms of likely bias as the setting of the study was a single fertility centre and data was the totally subjective response of the couples.

\section{CONCLUSIONS}

Inferences drawn from the findings suggest couples undergoing fertility treatment in western India reported poor QoL. Wives have poorer FertiQoL scores as compared to their partners. The study was instrumental in highlighting the colossal challenges and related poor quality of life which may be a contributory factor to non- conception and can gravely compromise the treatment outcomes.

\section{ACKNOWLEDGEMENTS}

This study is part of the first author's Ph D dissertation, from MGM Institute of Health Sciences, Navi Mumbai. A researcher is thankful to the parent institute for constant support. All the Reproductive medicine specialists, administrative authorities, participants, fertility centre staffs are immensely acknowledged for contributing to efficacious completion of the research study.

\section{Conflicts of interest: None}

Funding: None 


\section{Author Contributions}

Data Collection, Writing -original drafting: SB, Writing- review \& editing: MMN

\section{REFERENCES}

1. Estimates of fertility indicators. Encyclopedia Brittanica. 2019;29-66. Available from: https://www.censusindia.gov.in/ vital_statistics/SRS_Report_2017/10. Chap_3-Estimates of Fertility Indicators- $20 \overline{1} \overline{7}$

2. Prevalence of Infertility in India. National Health Portal https:// www.nhp.gov.in/disease/reproductive-system/infertility. 2016.

3. WHO. Health statistics and information systems. Metrics: Disability-Adjusted Life Year (DALY) [Internet]. 2012;0:2-3. Available from: http://www.who.int/healthinfo/global_burden_disease/metrics_daly/en/

4. Barani Ganth D, Thiyagarajan S, Ganth BD, Thiyagarajan S, Nigesh K. Role of infertility, emotional intelligence and resilience on marital satisfaction among Indian couples. International Journal of Applied Psychology. 2013;3(3):31-7.

5. Creswell JW. The Selection of a Research Approach. Research Design [Internet]. 2014;3-23. Available from: http://www.sagepub.com/upm-data/55588_Chapter_1_Sample_Creswell_Research_Design_4e.pdf

6. Boivin J, Takefman J, Braverman A. The fertility quality of life (FertiQoL) tool: Development and general psychometric properties. Human Reproduction. 2011;26(8):2084-91.

7. Sharma R. Revised Kuppuswamy's socioeconomic status scale: Explained and updated. Indian Pediatrics. 2017;54(10):867-70.

8. Moura-Ramos M, Gameiro S, Canavarro MC, Soares I, Almeida-Santos T. Does infertility history affect the emotional adjustment of couples undergoing assisted reproduction? the mediating role of the importance of parenthood. British Journal of Health Psychology. 2016;21(2):302-17.

9. Karabulut A, Özkan S, Oğuz N. Predictors of fertility quality of life (FertiQoL) in infertile women: Analysis of confounding factors. European Journal of Obstetrics and Gynecology and Reproductive Biology. 2013;170(1):193-7.

10. Jahromi BN, Mansouri M, Forouhari S, Poordast T, Salehi A. Quality of life and its influencing factors of couples referred to an infertility centre in Shiraz, Iran. International Journal of Fertility and Sterility. 2018;11(4):293-7.
11. Valsangkar S, Bodhare T, Bele S SS. An evaluation of the effect of infertility on marital, sexual satisfaction indices and healthrelated quality of life in women. J Hum Reprod Sci. 4(2)(2):805.

12. Desai HJ, Gundabattula SR. Quality of life in Indian women with fertility problems as assessed by the FertiQoL questionnaire: a single-centre cross-sectional study. Journal of Psychosomatic Obstetrics and Gynecology. 2019 Jan 2;40(1):82-7.

13. Rashidi B, Ramezanzadeh F, Montazeri A, Shariat M, Abedinia $\mathrm{N}$, Ashrafi M. Health-related quality of life in infertile couples receiving IVF or ICSI treatment. BMC Health Services Research. 2008;8:1-6.

14. Gao M, Ji X, Zhou L ZZ. The fertility quality of life (FertiQol) in Chinese infertile women. Transl Androl Urol. 2016;Apr;5(Supp(DOI: 10.21037/tau.2016.s084. PMCID):56-7.

15. Aarts JWM, Huppelschoten AG, van Empel IWH, Boivin J, Verhaak CM, Kremer JAM, et al. How patient-centred care relates to patients quality of life and distress: A study in 427 women experiencing infertility. Human Reproduction. 2012;27(2):488-95.

16. Santoro N, Eisenberg E, Trussell JC, Craig LB, Gracia C, Huang $\mathrm{H}$, et al. Fertility-related quality of life from two RCT cohorts with infertility: Unexplained infertility and polycystic ovary syndrome. Human Reproduction. 2016;31(10):2268-79.

17. Neumann K, Kayser J, Depenbusch M, Schultze-Mosgau A, Griesinger G. Can a quality-of-life assessment assist in identifying women at risk of prematurely discontinuing IVF treatment? A prospective cohort study utilizing the FertiQoL questionnaire. Archives of Gynecology and Obstetrics [Internet]. 2018;298(1):223-9. Available from: https://doi.org/10.1007/ s00404-018-4797-2

18. Taha EA, Sabry M, Abdelrahman IFS, Elktatny H, Hosny A. Impact of irregular marital cohabitation on quality of life and sexual dysfunction in infertile men from upper Egypt. Clinical and Experimental Reproductive Medicine. 2020;47(1):77-82.

19. Hsu PY, Lin MW, Hwang JL, Lee MS, Wu MH. The fertility quality of life (FertiQoL) questionnaire in Taiwanese infertile couples. Taiwanese Journal of Obstetrics and Gynecology. 2013;52(2):204-9.

20. Huppelschoten AG, van Dongen AJCM, Verhaak CM, Smeenk JMJ, Kremer JAM, Nelen WLDM. Differences in quality of life and emotional status between infertile women and their partners. Human Reproduction. 2013;28(8):2168-76. 